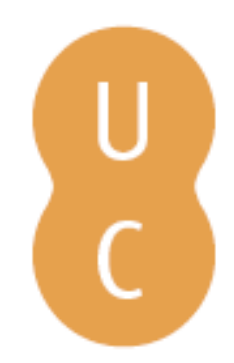

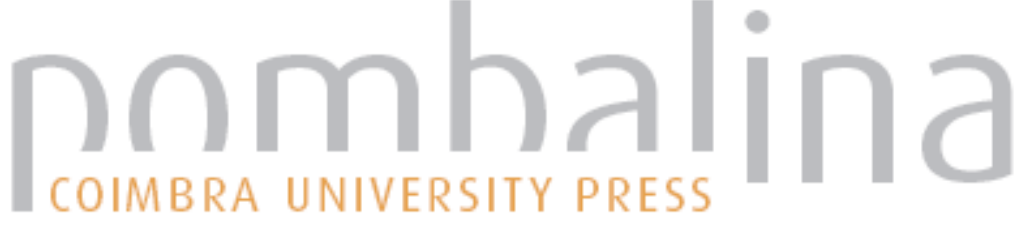

\section{Monoteísmo(s) e fundamentalismo(s)}

Autor(es): $\quad$ Magalhães, Isabel Allegro de

Publicado por: Imprensa da Universidade de Coimbra

URL

persistente: URI:http://hdl.handle.net/10316.2/30086

DOI: $\quad$ DOI:http://dx.doi.org/10.14195/978-989-26-0310-0_5

Accessed : $\quad$ 26-Apr-2023 16:24:00

A navegação consulta e descarregamento dos títulos inseridos nas Bibliotecas Digitais UC Digitalis, UC Pombalina e UC Impactum, pressupõem a aceitação plena e sem reservas dos Termos e Condições de Uso destas Bibliotecas Digitais, disponíveis em https://digitalis.uc.pt/pt-pt/termos.

Conforme exposto nos referidos Termos e Condições de Uso, o descarregamento de títulos de acesso restrito requer uma licença válida de autorização devendo o utilizador aceder ao(s) documento(s) a partir de um endereço de IP da instituição detentora da supramencionada licença.

Ao utilizador é apenas permitido o descarregamento para uso pessoal, pelo que o emprego do(s) título(s) descarregado(s) para outro fim, designadamente comercial, carece de autorização do respetivo autor ou editor da obra.

Na medida em que todas as obras da UC Digitalis se encontram protegidas pelo Código do Direito de Autor e Direitos Conexos e demais legislação aplicável, toda a cópia, parcial ou total, deste documento, nos casos em que é legalmente admitida, deverá conter ou fazer-se acompanhar por este aviso.

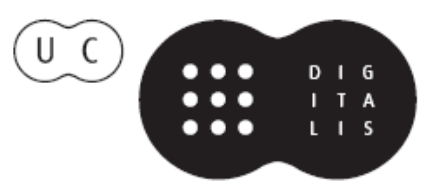




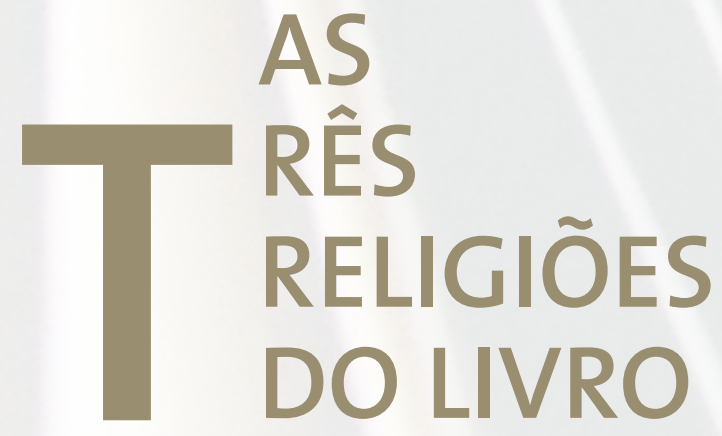

Anselmo Borges

João Gouveia Monteiro

COORDENAÇÃO 
Isabel Allegro de Magalhães ${ }^{14}$

\section{MONOTEÍSMO(S) E FUNDAMENTALISMO ( S )}

A difícil interrogação entregue aos três participantes desta Mesa O monoteísmo conduz ao fundamentalismo? - fez-me pensar na sábia frase de Tchouang-tseu, quando num texto taoísta sobre o Uno diz: Ficam as perguntas. Aguardam-se as respostas ${ }^{15}$. Talvez não seja possível mais do que isso mesmo, mas sossega-nos Hans-G. Gadamer, ao dizer que as perguntas hão-de condicionar as respostas.

\section{Monoteísmo(s) e fundamentalismo(s)}

Uma das coisas que pode suscitar a pergunta quanto a se há ou não no conceito e na prática do monoteísmo algo intrínseco que incite ao fundamentalismo e propicie violência em palavras e actos (para além das questões "de princípio", é claro) é o facto de, ao mesmo tempo, se presenciar duas coisas opostas: por um lado, conhecermos circunstâncias exemplares de grande respeito e admiração até entre os monoteísmos, e de estes para com outras religiões; por outro lado, sabermos que a maior violência religiosa exercida na História foi (e ainda é) levada a cabo por monoteísmos. (Naturalmente, sem aqui mencionar outras formas de violência, e não menor, totalmente autónomas em relação a religiões, ligadas a ideologias, elas próprias já quase "religião").

\footnotetext{
14 Universidade Nova de Lisboa.

15 Agradeço a Yvette K. Centeno o acesso a este texto.
} 
Numa resposta curta, diria que nada há num monoteísmo que intrinsecamente o torne fundamentalista ou incite a qualquer forma de violência (em qualquer caso, uma violência que é já política).

(Tomo aqui fundamentalismo como a atitude vinculativa, inegociável, autoritária perante um Texto Sagrado lido "literalmente", bem como a convicção argumentada de modo dogmático, por zelo religioso ou não.)

Numa resposta mais longa, direi que houve (e há) no monoteísmo elementos que - em si e potenciados por conjunturas históricas - favorecem posições fundamentalistas. Entre eles estão, a meu ver, os seguintes:

- dificuldade em reconhecer a alteridade (acentuada pelo facto de serem três os monoteísmos, e de descenderem uns dos outros - SIBONY: 1992);

- interpretações "literais" dos textos e da Tradição;

- teologias, doutrinas e normas que obscurecem a experiência do Mistério;

- missão suposta de converter o outro;

- pertença religiosa como identidade afectiva poderosa;

- noção teleológica do tempo e da vida.

Começo por algumas considerações gerais, para a seguir apresentar em poucas palavras esses pontos.

\section{Monoteísmo(s) e pluralismo}

Segundo fontes documentais, o primeiro monoteísmo da História foi o bíblico. Isto para além de outras hipóteses, não confirmadas: não só a de antes de este terem já existido monoteísmos no Egipto, Babilónia e outros lugares, como a de os politeísmos terem sido precedidos na História pela percepção de uma Divindade inicial, UNA, que só depois teria sido desdobrada noutras.

Sabemos que a passagem histórica do paganismo sírio-palestino ao monoteísmo bíblico foi gradual e longa (só no "Deutero-Isaías" se afirmará com clareza o monoteísmo, e só mais tarde ele se imporá. Por isso, em textos bíblicos anteriores ao exílio, como Jan Assman o faz notar, vê-se ainda a presença de politeísmos (ASSMAN: 2009, 49). 
A passagem fez-se em várias etapas: antes da clareza de um Deus único, passou-se do paganismo politeísta ao benoteísmo (reconhecimento de um Deus que se distingue dos outros) e à monolatria (adoração de um só deus no meio de outros (ASSMAN: 2009, 47). Ao longo dessas etapas vemos uma coexistência prolongada e pacífica de monoteísmo e paganismos, sem agressividade nem arrogância, sem que se pretenda eliminar a diversidade existente, como se vê no Salmo 82. Isso dá-se por se acreditar que todos os deuses são verdadeiros à sua maneira (ASSMAN: 2009, 17).

De muitos modos e em diferentes tempos e lugares (não sigo aqui uma cronologia, apenas um traçado temporal geral), foi-se perdendo a noção de que todas as verdades são relativas (não relativistas, mas relativas por estarem sempre ligadas a contextos). A afirmação monoteísta foi-se manifestando intransigente para com as religiões dos outros, avaliadas como falsas e tornadas inimigas, o que gera uma absolutização da fé (ASSMAN: 2009, 15). Vêmo-lo em várias narrativas, por ex., no "Livro da Sabedoria" (Sb 14). Contudo, a primeira agressão de Israel foi voltada para os de dentro, sendo "Canaan" símbolo do paganismo interno. Jan Assman afirma-o, citando o lema: "Há que exterminar o pagão que vive em cada um" (ASSMAN: 2009, 134)16.

O monoteísmo vem assim retirar às outras crenças as suas parcelas de verdade, justificando-o como obediência à lei de Deus. Nesses conflitos, porém, o que está verdadeiramente em causa é uma questão de poder político, étnico, cultural -, assente nessa convicção de que só existe um Texto Sagrado, uma só interpretação, uma só Revelação, ou seja: uma espécie de $U r$-fundamentalismo, as suas primícias ou os seus bastidores.

Quer na mesma zona quer noutros locais e tempos da História, houve casos em que a convivência inter-religiosa era genuína, espiritual, fecunda. Em vários momentos, a relação entre as três comunidades abraâmicas foi exemplar, do ponto de vista espiritual, religioso, cultural. Por ex., na Idade Média, sobretudo entre os sécs. IX e XI, em lugares da Andaluzia, as três comunidades

\footnotetext{
16 Curiosamente, Freud, por um lado, considera que o monoteísmo representou uma forma de violência para os judeus, obrigando-os a abdicar da representação plural de imagens e a aderir à noção abstracta da irrepresentabilidade divina do Deus único, com isso deixando a alma judaica privada da sua natural sensorialidade. Por outro lado, Freud pensa que o monoteísmo significou um progresso espiritual na Humanidade (ASSMAN: 2009).
} 
abraâmicas aí residentes relacionaram-se de modo fecundo, em termos humanos, literários e artísticos, científicos e espirituais. E também na Sicília houve experiências que hoje poderiam ser consideradas interculturais, em que não só se partilhava uma conviviabilidade como se debatia o pensamento, o que já antes acontecera em lugares do Médio-Oriente. Sobre isto são importantes as informações e as reflexões trazidas, por ex., pelos estudos de Michael A. Signer (HARKINS: 2010, 8), bem como, entre outros textos de José Mattoso, o que agora se publica nesta colectânea.

$\mathrm{Na}$ linha do pensamento produzido sobre estas questões no século $\mathrm{XV}^{17}$, o filósofo e místico alemão Nicolau de Cusa encena no livro A Paz da Fé um diálogo entre pessoas de vários povos e religiões (entre outros, um árabe, um caldeu, um judeu, um francês, um persa, etc.). O objectivo citado no parágrafo 1 apresenta um homem (possivelmente ele próprio) que, em consequência de uma prolongada e continuada meditação, diz, teve a visão de uma possibilidade inter-religiosa nova, que apresenta assim:

[...] mediante o talento de uns poucos sábios conhecedores de toda essa diversidade que se observa nas religiões do mundo, seria possível encontrar uma concordância e através dela estabelecer na religião a paz perpétua por um meio conveniente e verídico" (N. de CUSA: 2002, 21).

Quase só parafraseio João Maria André, ao dizer que duas linhas centrais de reflexão sobressaem em $A$ Paz da Fé: a afirmação de um só Deus, independentemente da diversidade de religiões, e a exigência de cada pessoa ceder em alguns aspectos, de forma a criar-se uma harmonia entre as diferenças. E o livro atribui na realidade um valor positivo à diferença, tornando-se por isso dinamizador da manutenção das identidades próprias. Nicolau de Cusa propõe uma atitude de respeito perante o outro, perante aquele que é diferente do eu que o vê e escuta e que, por sua vez, possui uma perspectiva própria (ANDRÉ: 2003, 13). E, por mais que essa perspectiva difira da nossa, só pelo facto de ser a de um outro, merece a nossa escuta e todo o respeito.

17 Dois textos de João Maria André, citados na Bibliografia, trazem elementos muito significativos sobre este ponto. Deles retiro aqui elementos. 
No século seguinte, Sir Thomas Morus confronta os cidadãos do lugar imaginário que a sua Utopia configura com a possibilidade de seguirem a religião que entenderem, reconhecendo em todas as religiões e cultos expressões diversas daquele "único Deus" que é "inexplicável”. Sugere até que seja construído um único templo, sem imagens nem marcas específicas de uma religião, de modo a todos os crentes poderem prestar os seus próprios cultos (ANDRÉ: 2003, 18-20), o que dá sinal do respeito pela diversidade cultural e religiosa. (É curioso que este lugar imaginário quinhentista evoca um outro, real e já do séc. XX, criado pelo Secretário-Geral das Nações Unidas na década de 70 - Dag Hammerskjöld: uma pequena sala, à entrada do edifício da ONU, em Nova Iorque, com idêntica finalidade: proporcionar a meditação de todos num lugar despido de todos os símbolos, vazio, que designou como "A room of quiet").

Também na Índia deparamos com elementos de tolerância e de harmoniosa articulação das diferenças. Em vários momentos da História, soube-se construir tecidos de diversidades. Foi o caso dos séculos XVI e XVII, em que se viveu um grande equilíbrio nas relações e respeito mútuo entre hindus e muçulmanos. Akhbar "o Grande", imperador mogol muçulmano, terá expressado uma visão que situa Deus para além de qualquer religião concreta, posição eventualmente decorrente da influência dos Sufis do Islão. Interessante é ver-se que, quando se atinge a possibilidade, conceptual e na praxis, de uma harmonia entre religiões e espiritualidades diversas, a presença de místicos esteve em geral por perto. E isso em todas as religiões. Antes de mais, a influência dos místicos deve-se à sua intuição de que Deus não é susceptível de ser apreendido, de que as religiões são apenas meios, de que o Absoluto é inatingível. ${ }^{18}$

Mas não foi só no passado que houve bons exemplos. Também nos nossos dias, em simultâneo com a violência conhecida, outras experiências existem.

\footnotetext{
${ }^{18}$ Lamentavelmente, e pelo próprio facto de os místicos viverem esse outro entendimento do Divino, descentrados de matérias doutrinais, livres em relação à instituição religiosa, pelo seu desprendimento e iluminação interior, o seu grau de liberdade dá-lhes uma imprevisibilidade nada controlável pelas suas hierarquias, católicas, islâmicas ou quaisquer outras. Possivelmente por isso, eles e elas, os místicos, são marginalizados pela instituição a que pertencem. Durante séculos ficaram, assim, marginalizados extraordinários patrimónios de pensamento e de espiritualidade.
} 
Entre tantas outras, a que o recente filme de Xavier Beauvais apresenta: a vida afectuosa e de partilha espiritual (rezavam em conjunto, ora na mesquita, ora no mosteiro) entre muçulmanos e monges cristãos-cistercienses franceses, numa aldeia da Argélia, nas últimas décadas do século xx. Algo que foi drasticamente interrompido pela guerra civil argelina, quando em 1996 milícias islamitas raptaram e assassinaram quase todos os monges da comunidade residente há décadas num pequeno mosteiro e com quem a população muçulmana mantinha grande sintonia.

Ora, havendo na História um pluralismo religioso harmoniosamente vivenciado pelos diferentes monoteísmos, não será que isso desdiz a afirmação primária de que estes serão sempre intrinsecamente fundamentalistas e, por isso mesmo, violentos?

\section{A potência múltipla do UM}

Nada parece impedir um monoteísmo de respeitar outros e de dialogar, disse no início. Isso apesar de o elemento "mono" (UM) no lexema monoteísmo poder, à partida, sugeri-lo. Será assim? Como figura do pensamento, o UM contém forças contrárias, "oscilando" entre exclusão / inclusão. É redutor, ao sinalizar o pensamento único, a verdade exclusiva e exclusivista, elimina diversidades e pluralismo. Simultaneamente, o UM é congregador, ao reunir pluralidades e ser potência de muitos. É o número da fusão amorosa (dois em UM), é número místico por excelência. Por ex., na Cabala, o UM é indicativo do princípio primeiro. E no pensamento místico do seiscentista Jacob Böhme (Yvette Centeno, minha Colega e Amiga, lembrou-mo a tempo), o UM aponta à noção de Ungrund, que é a de um não-terreno ou de um estádio anterior a qualquer desdobramento, à materialização ou a uma ordenação. Indica pois essa indiferenciação que precede o concreto das coisas, a unidade primordial anterior a toda a diferenciação. Para que o monoteísmo não precise de eliminar o que de si difere, isto é, outros monoteísmos ou politeísmos em cada uma das Tradições, o que é indispensável é que se pense numa chave hermenêutica não apenas plural, mas transcultural (Cfr.: ANDRÉ: 2003, 21). 


\section{A favor e contra o fundamentalismo}

1) A recusa do outro e a procura de Alteridade. A preferência pelo idêntico, não pelo que difere de si, parece ser um traço constante do humano. Freud comentou essa pulsão em vários lugares. Reconhecer a alteridade parece então resultar de uma aprendizagem cultural, que pode acontecer ou não. O preconceito em relação ao diferente, ao outro, resultará em parte de uma auto-afirmação ou narcisismo, ao mesmo tempo que acentua ainda estes traços. E sem dúvida que isto propicia o fundamentalismo: o igual declarado como melhor que o diferente, nós afirmados como melhores do que eles. Da mesma maneira no campo do religioso: o que é semelhante a nós, o mesmo ou a mesmidade, aparece como superior, desvalorizando-se quase sempre o que difere de "nós".

Contudo, a ligação ao Divino é exactamente uma abertura à alteridade. Só que aí estamos perante o absoluto da Alteridade. E perante o Absoluto resta o gesto de acolher, imaginando-se que o Divino integra toda a multiplicidade e diversidade da Terra e do Cosmos, todos igualmente reconhecidos e incorporados.

2) A teologia como força e a fragilidade na relação ao Mistério. A afirmação racionalizada de uma ideia de Deus corre o risco de levar a fundamentalismos específicos. Aliás, em muitos casos foi isso que fez a teologia. Esta, gerada num quadro conceptual grego, e não no cristão, definiu doutrinas e dogmas, isto é, certezas, que contribuíram para acentuar no monoteísmo cristão a força de um totalitarismo. (E posições semelhantes provocaram idênticos efeitos nos outros monoteísmos). Por isso, a teologia, quando procedeu de modo especulativo em excesso, em vez de iluminar, quase obscureceu a noção do Divino, dissipando a dimensão experiencial. E a experiência do amor do outro é que constitui, de acordo com os evangelhos, a experiência e o conhecimento de Deus por excelência: "Quem não ama a seu irmão que vê, como pode amar a Deus que não vê?" (1 Jo 4, 20). Só que a força dessa experiência é de uma outra ordem: é da ordem da fragilidade; na fragilidade está a sua força.

3) Letra violenta e leitura infinita. Quase sempre os Textos Sagrados têm uma dimensão simbólica, impeditiva da interpretação rente à letra, 
visto que ela ocultaria outras camadas de significação. Embora uma leitura literal disponha também de uma hermenêutica, a leitura predominantemente literal, pelo próprio facto de permanecer ao rés do texto, violenta essa letra em vez de nela descobrir vida. (Note-se aqui o cuidado a ter com o facto de "vida" e "violência" provirem da mesma raiz grega: bios / bia). Pior ainda quando o texto é lido como voz do próprio Deus: aí a ameaça fundamentalista torna-se mesmo performativa, agindo independentemente de quaisquer contextos. Entra-se assim num terreno que já excede o religioso: é o da política e da vontade de poder. Nada de espiritual passa por aí.

Deparamos, contudo, com outras formas de ler que claramente afastam todo o fundamentalismo, por serem formas livres, abertas e críticas. Em todos os monoteísmos e em cada uma das tradições abraâmicas encontramos essas leituras, em nada impositivas.

No judaísmo, a interpretação midráshica abre o Texto a muitas possibilidades de sentido, numa espécie de infinitização da leitura (o Talmud é exemplo), o que tem um paralelo na ijtihad vivida no Islão (BORGES: 2010, 84). No Islão, com Averrois, acolhemos essa visão de abertura, tal como no judaísmo o encontramos em Spinoza e entre tantos outros que procederam à análise crítica dos Textos.

(Por analogia, pressente-se aqui algo coincidente com aquilo a que Maria Gabriela Llansol chamou a posição legente: atitude de disposição para a escuta, acolhedora de "dissonâncias", transfigurando-as, na disponibilidade de que o texto transforme por dentro.)

No cristianismo, antes do livre exame de Lutero e para além dos usos restritos de métodos histórico-críticos, a via apofática ou da teologia negativa é seguramente a que melhor manifesta abertura, precisamente por suspender a possibilidade de se "dizer Deus", mantendo uma posição humilde perante o Mistério. Na realidade, não há Tradição religiosa que seriamente fale de Deus sem reconhecer que todas as metáforas indicativas do Divino são intrinsecamente limitadas e sem dizer a experiência de um absconditus Deus, Deus oculto, que assim permanece apesar das revelações (SCHILLEBEECKX: 2007, 416).

Sempre os houve, mas hoje de novo é possível ler diversos teólogos católicos que estão nos antípodas de qualquer fundamentalismo: convictos 
de que a letra é a cada instante soprada pelo Espírito que age no mundo e no mais íntimo de cada um, sabedores de que a revelação é "um processo maiêutico" (TORRES QUEIRUGA: 2007, 226) ou "uma maiêutica da História" (BORGES: 2010, 103). Vejamos excertos de algumas dessas vozes:

Schillebeeckx.

A auto-revelação de Deus é dada em experiências humanas interpretadas. Nunca temos acesso à "Palavra de Deus" de modo imediato. Estritamente falando, a Bíblia não é a Palavra de Deus, mas um conjunto de testemunhos de fé de crentes que se situam numa tradição particular da experiência religiosa. (SCHILLEBEECKX: 2007, 410)

\section{Andrés Torres Queiruga:}

Um texto religioso é uma interpretação bumana da realidade: da realidade comum, a única que existe e na qual todos e todas vivemos. O que a caracteriza [... é] a convicção de que a dimensão empírica [...] não esgota a totalidade da realidade. [...] Trata-se, pois, de uma interpretação que se apoia na convicção e na descoberta de uma Presença não visível em si mesma, mas implicada no que se vê. [...] (TORRES QUEIRUGA: 2007, 225-26)

Anselmo Borges:

À luz da libertação final que implica uma antropologia e uma teologia negativa, os livros sagrados são também a história da tomada de consciência por parte dos humanos do que Deus, o Sagrado, não é, e do que eles para se tornarem verdadeiramente humanos não são. (BORGES: 2010, 86)

4) Conversão e respeito pela diferença. De interpretações rentes à letra e desatentas dos contextos, ou seja, fundamentalistas, surgiu em vários tempos da História uma espécie de impulso "imperial" que impelia a impor a própria religião, cuidando que só ela deveria tornar-se a religião de todos, por só ela ter valor universal. Vêmo-lo no cristianismo como no islão. (No judaísmo, assumirá outras modalidades.)

O cristianismo, ao afirmar-se como a "única religião verdadeira", estava convicto de que "fora da Igreja não há salvação" - ao que o teólogo 
Schillebeeckx, com um sentido maior da Incarnação, contrapõe: "Também fora do mundo não há salvação”. Tal convicção levou aos horrores das perseguições, às conquistas, à eliminação de dissidentes ou simplesmente do outro, nas Cruzadas, com a Inquisição, em situações de evangelização nas colónias com limpezas religiosas, étnicas, culturais. Na expressão de Jan Assman, tratava-se de uma semântica cultural que exibia a exclusão e a militância em ordem à conversão (ASSMAN: 2009, 150). Também hoje há casos equivalentes, em cada monoteísmo à sua maneira, em graus diversos mas nem sempre menos violentos. É que o objectivo de "converter" (mesmo se a uma verdade considerada mais elevada) é sempre violento, profanação até de um sentido de Deus, ao supor alguma arrogância, mesmo se ela se apoia na fé. Acima de tudo, manifesta a perda do sentido do Mistério: Deus para além de toda a Revelação. E não sendo Deus "monopólio" de nenhuma religião, o objectivo missionário da "conversão" de outros (crentes de outras religiões ou não-crentes) a uma religião (que é sempre "a própria" ou "a minha”), não tem razão de ser. (Uma outra coisa é o sentido de se poder despertar no outro a questão do Sentido para além de todos os sentidos, com nome ou sem nome: despertar essa experiência de abertura ao Mistério.)

O que falta será antes uma outra conversão, a de todos e cada pessoa, dentro da própria religião, uma conversão no sentido da mudança de vida que possa repor dimensões essenciais da mensagem central das religiões abraâmicas:

Conversão a um amplo sentido ético, de modo a criar condições de justiça e fraternidade no mundo.

Conversão a uma espiritualidade livre da tentação doutrinária e verdadeiramente sapiencial, que saiba reverenciar tudo o que na História e em cada pessoa eleva o humano que se eleva ao Divino.

Conversão da comunidade dos crentes para que exerça com pertinência e competência uma função crítica da História e do que nela violenta as vidas, o mundo e o próprio cosmos.

5) Identidades religiosas: afecto vital e violência. Uma outra ordem de factores propícios ao fundamentalismo resulta de conjunturas da História em que a força identitária que uma religião pode projectar é politicamente aproveitada e potenciada. Pela antropologia e a sociologia, sabemos que uma 
religião, sobretudo se monoteísta, pode constituir para a sua comunidade uma força identitária poderosa, estruturante da identidade, a individual e a partilhada. Poderosa, a ponto de criar nas pessoas um subterrâneo afectivo não comparável ao de qualquer envolvimento, político ou outro. Isso pode permitir congregar as vontades dos crentes em uníssono para a violência; e (estranhamente) tanto mais motivados quanto mais violenta for a situação. É que essa violência pode ser "terapêutica", isto é, vivida por uma comunidade como uma operação de transfert colectivo. Quem o diz é René Girard, no seu livro La Violence et le sacré (GIRARD: 1972, 18). E esse transfert faz-se sempre à custa de uma vítima (em geral exterior à comunidade), vítima que pode libertar rancores, humilhações, tensões internas da própria comunidade. Possivelmente derivado da ideia do sacrifício ritual (que nunca foi avaliado como violento, mas como apaziguador), o discurso institucional legitima tais actos, racionalizando-os com argumentos religiosos superiores. Isso proporciona aos crentes e à instituição que tal violência assuma um carácter sagrado, o que a torna irrecusável. O fenómeno tem estado à vista em cenários vários da contemporaneidade e foi designado como "violência religiosa", por ser assumida "em nome de" Deus (ASSMAN: 2009, 29).

Poderá pensar-se que a mesma energia afectiva poderá vir a ser alcançada como força de sinal diferente, alquímica e espiritualmente transformadora, de si e da vida, feita assim fermento ou semente de uma outra Terra, viva e justa, para com a diversidade humana e religiosa do mundo.

6) Eschaton e reincarnação. Outro dos elementos potenciadores de fundamentalismo é o sentido teleológico da existência. A concepção linear do tempo e da História, partilhada pelas três religiões do Livro, coloca os crentes perante as noções de um eschaton e de um apocalipse, que firmam a ideia de que a existência individual tem um fim e de que existe um horizonte final para a História. Em termos heideggerianos, a ideia do humano como Sein-zum-Tod (ser-para-a-morte) sublinha uma dimensão de angústia existencial, por a morte surgir como definitiva. Essa noção do "definitivo" traz ainda consigo uma espécie de sentido de missão: a de "em tempo útil" tentar "converter o maior número de pessoas, por se acreditar que se está de posse da "Verdade" total. Esse propósito pode mesmo desrespeitar as naturais diferenças culturais 
e pessoais, ao tornar-se um imperativo categórico da consciência cristã. Mas o sentido teleológico pode levar noutro sentido e vincar a responsabilidade dos cristãos pelo rumo da História, no sentido de criar sociedades mais justas, mais respeitadoras da pluralidade cultural e religiosa.

No Extremo-Oriente, pelo contrário, a concepção do tempo e da vida liberta desse sentido de urgência e da ideia de uma missão exterior a cumprir. A visão do tempo e da vida, predominantemente circular e cíclica, concebe a História como a sucessão de ciclos e a vida individual com a possibilidade de uma reincarnação, caso a alma, depois da morte corpórea, não tenha atingido um estádio espiritual elevado. Nesse caso, poderá regressar à Terra e recomeçar outro ciclo. Não se concebe, pois, que o Ser de cada um se jogue numa só vida. A roda do tempo dará outras oportunidades, sendo a metempsicose esse recomeço. Eventualmente, isso garante maior impassibilidade e atenua a angústia perante a ideia de um fim irrevogável. Talvez por isso não figure nas espiritualidades do Extremo-Oriente idêntico sentido de responsabilidade perante a História, nem tão pouco qualquer intenção de "salvar" outros pela sua conversão religiosa.

\section{Diferentes caminhos, um só Cume}

A pergunta que aqui nos trouxe suscita o oposto do fundamentalismo. Ela impele, pelo contrário, à consciência de que múltiplas são as expressões do humano e diversas as percepções do Mistério. Reconhecemos que as religiões são instrumentos auxiliares de um caminho em direcção ao Mistério de Deus e que cada religião partilha de uma parcela apenas desse Mistério (PANIKKAR: 2006, 16). Sabemos também que muitos são os nomes para o Divino, mas que o Divino está para lá de todos os nomes. Por isso, a posição que nos cabe é a de uma humildade teológica essencial.

Assim, poderemos dizer com Schillebeeckx:

Há sempre mais verdade na pluralidade do conjunto das religiões mundiais do que numa só religião particular, e o Cristianismo não constitui excepção. (SCHILLEBEECKX: 2007, 416) 
E com Raimon Panikkar - místico e teólogo que há poucos meses passou a esse tempo já definitivo - é possível ouvirmos a sinfonia em que cada religião entra com o seu instrumento e a sua melodia:

A questão não é a de falarmos a mesma língua ou linguagem, nem de praticarmos a mesma religião. É uma questão de permanecermos com uma consciência desperta, conscientes de estarmos a entoar notas diferentes na mesma sinfonia, e de que, por diferentes caminhos, caminhamos para o cume - que é o mesmo. [...] (PANIKKAR: 1990a, par. 11)

[...] uma religião única e universal representaria um empobrecimento da tão rica experiência religiosa da Humanidade; [...] nem a unidade humana nem a religiosa pertencem à ordem do discurso ou à ordem do pensamento; não têm a ver com a ordem do logos, mas com a realidade do Espírito que não se sabe de onde vem nem para onde vai. [...] (PANIKKAR: 2006, 15-16)

Assim, a situação multicultural e intercultural em que vivemos exige dos que desejam voltar-se para Deus um passo novo em direcção à Paz.

Exige também, sobretudo para as gerações mais jovens, uma reescrita de cada Tradição - segundo Michael Signer, estudioso das relações judeo-cristãs, é uma tarefa primordial que nos cumprirá realizar (BAND: 2010, 32).

Ora neste ponto de (des)equilíbrio do mundo, das culturas e das religiões, a peça setecentista Nathan, o Sábio (Nathan, der Weise), de Lessing, volta a ser sugestiva.

Curiosamente, João Maria André falou dela em 2003, na conferência que fez no Terraço (Centro do Graal em Lisboa) sobre o multiculturalismo (ANDRÉ: 2003, 29-30). E de novo em 2010, Anselmo Borges, neste livro que acaba de publicar, dá-lhe substancial relevo (BORGES, 2010: 128-131). E também eu agora queria convocá-la, justamente por a peça encenar um diálogo em que participam, além de outros, três representantes (como nós nesta Mesa) das três religiões abraâmicas: um judeu de Jerusalém (o Sábio Nathan), um muçulmano (o Sultão Saladino) e um cristão. E, a dada altura, às perguntas do Sultão sobre qual a fé que mais o iluminara e sobre qual 
das três religiões será a verdadeira - visto que, a seu ver, uma só poderia sê-lo ${ }^{19}$, Nathan responde através de uma parábola reveladora de reverência perante as duas outras religiões. E o que preside à sua narrativa é a ideia de que a superioridade de uma religião só pode avaliar-se pela vida, isto é, pelo exercício prático da virtude.

E fecho estas palavras com um texto que será também pronunciável pelos crentes das religiões abraâmicas e ainda pelos de outras Tradições.

De algum modo, o enunciado constitui um texto que poderá ser rezado como a "Shahada" muçulmana, que também se inspira no evangelho de "João" e este, por sua vez, no livro do Deuteronómio, conforme mostra Jean-Yves Leloup (LELOUP: 2010, 786).

\section{"Shahada"}

Si, devant témoin, je devais confesser ma foi, mon chemin ou ma Shahada, je dirais:

Il n'y a pas d'autre Dieu que Dieu: YHWH,

Abba, Allah. Il a tous les noms et Il est au-delà

de tous les noms;

il n'y a pas d'autre réalité que la Réalité;

ce qui est, est; ce qui n'est pas, n'est pas

ni ceci, ni cela, c'est ainsi

Moise, Jésus, Mahomet en sont les témoins

(et à leurs noms, "béni sont-ils ", j'en ajouterais

certainement

quelques autres: Abraham, David, Salomon, Jérémie,

Isaïe, Ézéquiel, Roumi, Ibn Arabi, Hallaf, Maître Eckhart, Séraphin de Sarov,

Thérèse de Lisieux, mais aussi Lao-Tseu, Bouddha, Nagarjuna...) (LELOUP, 2010, 788 20).

19 Lessing, 1962, 5er Auftritt, 66-67: "Saladin: Was für ein Glaube,/ [...] Hat dir am meisten eingeleuchtet?] [...] // "Der Christ ist zwischen uns. - Von diesen drei/Religionen kann doch eine nur / Die wabre sein. - [...]."

${ }^{20}$ Agradeço à minha Amiga Celeste Isabel de Sousa Lopes a indicação tão oportuna deste texto. 


\section{BIBLIOGRAFIA}

AAVV. 2007. Deus no Século XXI e o Futuro do Cristianismo. Coord. e "Introdução" de Anselmo Borges. Porto: Campo das Letras.

ANDRÉ, João Maria. 2003. Ecumenismo, Multiculturalismo e Educação Intercultural. Ed. I. Allegro de Magalhães. Lisboa: Graal-Publicações Terraço (17).

(Idem) 2007. "Identidade(s) e Multiculturalismo(s): os desafios da mestiçagem à Igreja do presente". In AAVV. 2007. Deus no Século XXI e o Futuro do Cristianismo. Coord. e "Introd.". Anselmo Borges. Porto: Campo das Letras, 151-196.

ASSMAN, Jan. 2009. Violence et monothéisme. Paris: Bayard.

BAND, Arnold J. 2010. "The making of a medievalist". In Harkins, Franklin T. (Ed.). Transforming Relations: Essays on Jews and Christians throughout History in Honor of Michael A. Signer. Forward by John Van Engen. Notre Dame, Indiana: Univ. of Notre Dame Press, 25-33.

BORGES, Anselmo. 2010. Religião e Diálogo Inter-religioso. Coimbra: Imprensa da Universidade.

CLAVEL, Juan María. 2007. "Decálogo de vivências entre Oriente e Ocidente". In AAVV: 197-202.

CUSA, Nicolau de. 1998. A Visão de Deus (Paris, 1514). Trad. e "Introd." de João Maria André. "Pref." de Miguel Baptista Pereira. 2a ed.; Lisboa: Fundação C. Gulbenkian.

(Idem) 2002. A Paz da Fé seguida de Carta a João Segóvia. Trad. e "Introd." de João Maria André. Coimbra: Minerva.

FREUD, Siegmund. 1986. L'Homme Moïse et la religion monothéiste. Trois essays. 1939; Trad. C. Heim. Paris: Gallimard.

GIRARD, René. 1972. La Violence et le sacré. Paris: Grasset.

HARKINS, Franklin T. 2010. "Introduction: The transformative work of Michael A. Signer». In Harkins, Franklin T. (Ed.).Transforming Relations: Essays on Jews and Christians throughout History in Honor of Michael A. Signer. Forward by John Van Engen. Notre Dame, Indiana: Univ. of Notre Dame Press, 1-22.

LELOUP, Jean-Yves. 2010. Dictionnaire amoureux de Jérusalém. Paris: Plon.

PANIKKAR, Raimon. 1990. "The Religion of the Future or the Crisis of the Notion of Religion: Human Righteousness”. Part I. In Interculture, Vol. XXIII (2), Spring: 1-24. Trad. IAM.

(Idem) 2006. The Experience of God. Icons of the Mystery. Trans. Joseph Cunneen. Minneapolis.

SCHILlEBEECKX, Edward. 2007. "A identidade cristã: desafio e desafiada. A propósito da extrema proximidade de Deus". In AAVV, 2007: 405-429.

SCHMIDT, Konrad. 2006. "Gibt es 'Reste hebräischen Heidentums' im Alten Testament?". In Primäre und sekundäre Religionen als Kategorie der Religionsgeschichte des Alten Testaments. Ed. Andreas Wagner. Berlin-NY: de Gruyter.

SIBONY, Daniel. 1992. Les Trois monothéismes. Juifs, chrétiens, musulmans entre leurs sources et leurs destins. Paris: Seuil.

TORRES QUEIRUGA, Andrés. 2007. "Depois do fim do Cristianismo pré-moderno, o quê?”. In AAVV. Deus no Século XXI e o Futuro do Cristianismo. 41-64. 